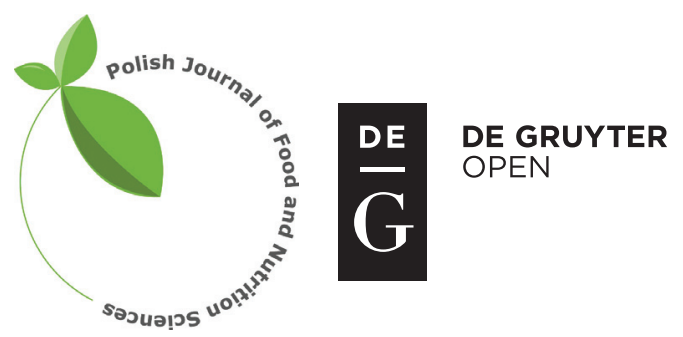

Pol. J. Food Nutr. Sci., 2016, Vol. 66, No. 2, pp. 85-91

DOI: $10.1515 /$ pjfns-2015-0053 http://journal.pan.olsztyn.pl

Review article

Section: Food Chemistry

\title{
Comparison of Phenolics and Phenolic Acid Profiles in Conjunction with Oxygen Radical Absorbing Capacity (ORAC) in Berries of Vaccinium arctostaphylos L. and V. myrtillus $\mathrm{L}$.
}

\author{
Nesrin Colak ${ }^{1}$, Hülya Torun ${ }^{2}$, Jiri Gruz ${ }^{3}$, Miroslav Strnad ${ }^{3}$, Michaela Subrtova ${ }^{3}$, \\ Huseyin Inceer ${ }^{1}$, Faik Ahmet Ayaz ${ }^{1 *}$
}

\author{
'Department of Biology, Faculty of Science, Karadeniz Technical University, 61080 Trabzon, Turkey \\ ${ }^{2}$ Biosystems Engineering, Faculty of Agriculture and Natural Sciences, Düzce University, 81620 Düzce, Turkey \\ ${ }^{3}$ Laboratory of Growth Regulators, Centre of the Region Haná for Biotechnological and Agricultural Research, \\ Institute of Experimental Botany, ASCR \& Palacký University, Olomouc, Czech Republic
}

Key words: blueberry, bilberry, phenolic acids, antioxidant capacity, Vaccinium

Caucasian blueberry (Vaccinium arctostaphylos L.) and bilberry (V. myrtillus L.), both native to Turkey, were evaluated for their total phenolics (TP) and anthocyanin (TAC) contents. Individual compositions of free phenolic acids and phenolic acids liberated from ester and glycoside forms were analyzed using UPLC-MS/MS. Berry extracts of each species were separated into three different fractions (sugar/acid, polyphenolic and anthocyanin) by solid phase extraction (SPE). The anthocyanin fractions of each species had the highest level of TP and TAC contents and ORAC values. Each species contained 10 phenolic acids representing each fraction, but in different quantities. The phenolic acids liberated from the esters and glycoside forms were caffeic acid and $p$-coumaric acid. The fractions containing phenolic acids liberated from ester and glycoside forms had a higher antioxidant capacity than that from free phenolic acids. The data suggest that both berries have potential as good dietary sources of phenolic antioxidants.

\section{INTRODUCTION}

Due to their high levels of beneficial nutrients and bioactive phytochemicals, especially anthocyanins, blueberries have received considerable attention in research into antioxidants studies for the last two decades since their potential role in the prevention of chronic diseases has been realized. Investigations of these non-nutrient biologically active compounds have revealed that native or improved blueberry varieties with high quality phenolics are associated with high antioxidant activity.

Phenolic contents of Vaccinium berries (e.g. anthocyanins, flavonoids, coumarins, lignans and benzoic acids) are well documented in the literature [Su, 2012; Yuan et al., 2011]. Many studies have investigated the contents and composition of the phenolic acids, anthocyanins and flavonoids of Vaccinium berries [Su, 2012; Primetta et al., 2013]. Anthocyanins are one of the major constituents in blueberries and are responsible for their red, blue, purple and black colors. The health benefits of Vaccinium berries, and in part of the leaves, attributable to their polyphenols and high natural anthocyanin contents include reducing the risk of coronary heart disease, inhibiting platelet aggregation, protecting arterial endothelial cells, reducing the risk of cancer and inflammatory insult, modulating the immune

\footnotetext{
* Corresponding Author: faa@ktu.edu.tr (Faik Ahmet Ayaz, Ph.D.) tion with antioxidant capacity.

system, enhancing eye function and retarding neurological disorders [Yuan et al., 2011; Primetta et al., 2013]. Apart from the health benefits, the berries of Vaccinium are an important source of food colorants and pharmaceutical ingredients [Li et al., 2011].

More recently, the anthocyanin compositions of both Caucasian blueberry (V. arctostaphylos L.) and bilberry (V. myrtillus L.) have been well documented [Lätti et al., 2009; Primetta et al., 2013]. Considering the growing interest in the potential nutraceutical properties of berries, it seems desirable to characterize the phenolics/anthocyanins of wild populations of Caucasian blueberry and bilberry growing in the north and mid-west of Turkey. The present study compared the two native berries that are widely distributed in these regions of Turkey. The objective of the study was to compare: (1) total phenolics (TP) and anthocyanins (TAC) contents in the two berry extracts and three different fractions thereof (sugar/ acid, polyphenolic and anthocyanin) by solid-phase extraction (SPE), (2) to determine the free phenolic acids and phenolic acids liberated from the free esters and glycoside forms by ultra performance liquid chromatography-tandem mass spectrometry (UPLC-MS/MS), and (3) to measure the oxygen radical absorbing capacity (ORAC) of the berry extracts and their different phenolic fractions. In view of the growing interest in these compounds, there is now an urgent need to identify and quantify these important compounds in conjunc- 


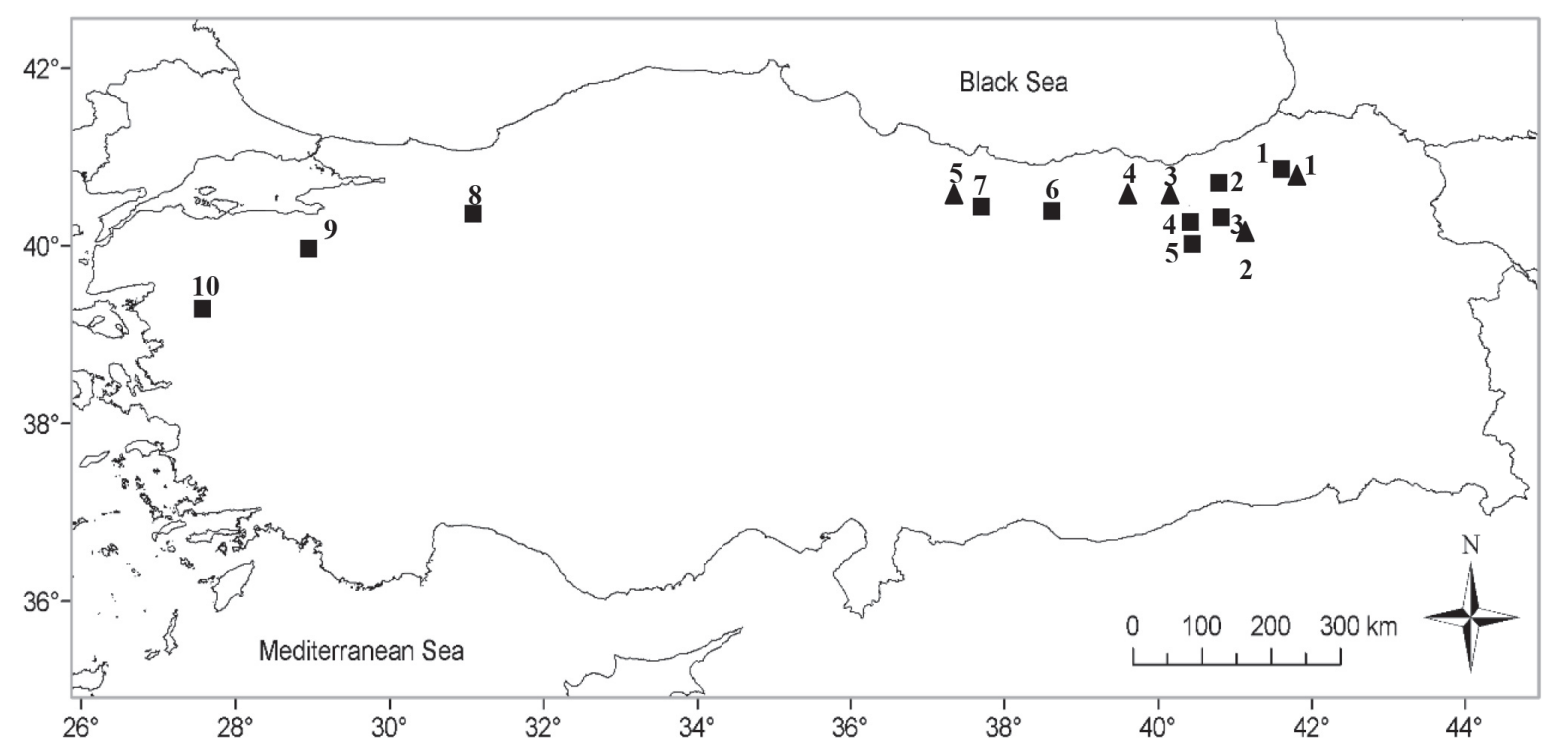

FIGURE 1. Natural distribution and geographic location of bilberry (Vaccinium myrtillus L.) (.) and Caucasian blueberry (Vaccinium arctostaphylos L.)

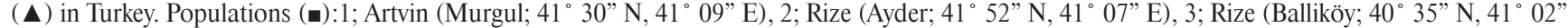

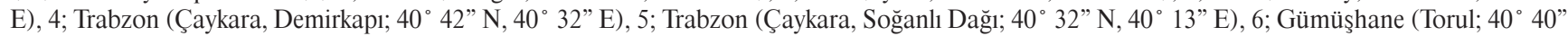

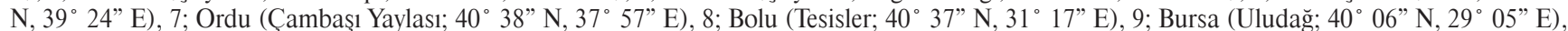

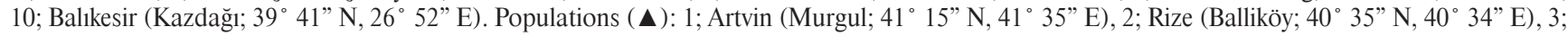

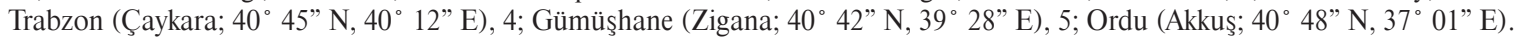

\section{MATERIALS AND METHODS}

\section{Plant material}

Five wild Caucasian blueberry ( $V$. arctostaphylos L.) and 10 bilberry ( $V$. myrtillus L.) populations were selected from northeastern and western Anatolia, Turkey (Figure 1). The ripe berries of the two species were collected as bulk population samples in their native habitats at altitudes of 600 -1250 and 1300-2900 m (a.s.1.) near the cities of Artvin, Rize Trabzon, Gümüşhane, Ordu, Bolu, Bursa and Balıkesir in August 2007 and 2008. The berry samples were hand-picked on sunny days in late morning. At each sampling location, berries were picked from six different areas, the distance between each area at a given location being greater than $100 \mathrm{~m}$. Approximately 100 berries of moderate size were collected from each area. The sampled berries were immediately pooled and kept in cold below $+4^{\circ} \mathrm{C}$ and transported to the local and main laboratories within approximately $2 \mathrm{~h}$. In the laboratory, the berry samples were treated with liquid nitrogen and stored at $-80^{\circ} \mathrm{C}$ in nylon boxes and supported by silica gel until analysis.

\section{Chemicals, reagents and solvents}

Analytical grade standards of 3,5-dihydroxybenzoic, gallic, protocatechuic, 4-hydroxybenzoic, 3-hydroxybenzoic, gentisic, 2-coumaric, 4-coumaric, caffeic, ferulic, syringic, sinapic, chlorogenic, salicylic, trans-cinnamic, and 3-coumaric acids were purchased from Sigma-Aldrich Fine Chemicals (St. Louis, MO, USA). Deuterium-labeled standards of 4-hydroxybenzoic acid (2,3,5,6-D4) and salicylic acid (3,4,5,6-D4) were purchased from Cambridge Isotope Laboratories (Andover, MA, USA). Formic acid and acetonitrile for HPLC were purchased from MERCK (Darmstadt, Germany) and deionized water was prepared using a Simplicity 185 deionizer (Millipore, Bedford, MA, USA).

\section{pH and titratable acidity (TA)}

For the measurement of both $\mathrm{pH}$ and titratable acidity (TA), the AOAC methods [AOAC, 2003], were followed with slight modifications. Half kilogram of each fresh berry was juiced using a commercial fruit juicer (Tefal ZE585, France). Portions of $30 \mathrm{~mL}$ of juice were placed in a glass beaker on a thermostatically-controlled electric hotplate at $37^{\circ} \mathrm{C}$ and $\mathrm{pH}$ were determined using an MP220 pH meter (Mettler Toledo). Before reading the $\mathrm{pH}$, each sample was agitated (using a magnetic stirrer) gently for $2 \mathrm{~min}$ until a constant reading was obtained. For measurement of TA, the solution $(100 \mu \mathrm{L}$ juice $+100 \mathrm{~mL}$ of $\mathrm{CO}_{2}$-free distilled water) were titrated with $0.1 \mathrm{~mol} / \mathrm{L} \mathrm{NaOH}$ to $\mathrm{pH}$ 8.2. TA was expressed as citric acid equivalents (CAE) per $100 \mathrm{~g}$ of fresh weight (FW) of berries. Each berry sample was analyzed in triplicate.

\section{Extraction}

Extracts of phenolic compound were prepared by modifying the method described by Rodriguez-Saona \& Wrolstad [2001]. Approximately $20 \mathrm{~g}$ of berry was liquid nitrogen-powdered in a mortar and pestle. Next, $30 \mathrm{~mL}$ of the extraction solvents (deionized water, $70 \% \mathrm{v} / \mathrm{v}$ aqueous acetone and $70 \%$ $\mathrm{v} / \mathrm{v}$ aqueous methanol, separately, one after the other) were added to the ground berries. Samples were then re-extracted until the solution became colorless. The homogenates were centrifuged at $7000 \times g$ for $20 \mathrm{~min}$ at $+4^{\circ} \mathrm{C}$. The supernatants with acetone and methanol were concentrated using a rotary evaporator (Heidolph Instruments $\mathrm{GmbH} \& \mathrm{Co}$. KG, Germany) at $38^{\circ} \mathrm{C}$ under partial vacuum. The combined aqueous supernatant and residues after acetone and methanol evaporation were dried using a freeze-dryer (Christ, Alpha 1-2LD plus, Germany), diluted to $30 \mathrm{~mL}$ with deionized water and then stored at $-80^{\circ} \mathrm{C}$ until analysis. 


\section{Solid-Phase Extraction (SPE)}

Extracts of phenolic compounds from both species were fractioned by solid-phase extraction with Grace Pure C-18 columns (max $500 \mathrm{mg}$ packed bed, $3 \mathrm{~mL}$, Deerfield, IL, USA). Solid-phase extraction columns were rinsed with $100 \%$ and $80 \%$ methanol $(5 \mathrm{~mL})$ and activated with deionized water $(5 \mathrm{~mL})$. The aqueous combined extract was then passed through columns. SPE was carried out as described by Rodriguez-Soana \& Wrolstad [2001]. Phenolic compounds were absorbed onto the columns, while sugars and other polar compounds were eluted with deionized water (aqueous fraction). The second fraction was eluted from the columns with $6 \mathrm{~mL}$ of ethyl acetate (polyphenolic fraction). The ethyl acetate was evaporated, and the residue was re-dissolved in $5 \mathrm{~mL}$ of $100 \%$ methanol. Next, $6 \mathrm{~mL}$ of acidified $(0.01 \%$ $\mathrm{HCl}$ ) methanol was used to obtain the third fraction (anthocyanin fraction). Subsequently, the methanol was evaporated using a rotary evaporator (Heidolph Instruments $\mathrm{GmbH} \&$ $\mathrm{Co} . \mathrm{KG}$, Germany) at $38^{\circ} \mathrm{C}$, and the fraction was re-dissolved in $5 \mathrm{~mL}$ of $100 \%$ methanol. All samples were stored at $-80^{\circ} \mathrm{C}$ until analysis.

\section{Determination of total anthocyanin (TAC) and total phenolic (TP) content}

TAC contents of extracts were measured using the $\mathrm{pH}$ differential method applicable to monomeric anthocyanin determination [Giusti \& Wrolstad, 2001]. Absorbance was read at 520 and $700 \mathrm{~nm}$ at $\mathrm{pH} 1.0$ and 4.5. TAC was expressed as milligrams of cyanidin 3-glucoside equivalents $(\mathrm{C} 3 \mathrm{G}, \mathrm{MW}=449.2$ and extinction coefficient $(\varepsilon)=26.900)$ per 100 grams FW of berries. TP content was measured with Folin-Ciocalteu (FC) reagent using the method described by Slinkard \& Singleton [1977]. Absorbance was measured at $750 \mathrm{~nm}$ using a UV-VIS spectrophotometry (Thermo, Evolution 100, England). TP was expressed as milligrams of gallic acid equivalents (GAE) per 100 grams FW of berries.

\section{Fractionation of phenolic acids}

Phenolic acids of berry extracts were fractionated as free, esterified and glycosided phenolic acids using previously described methods [Cvikrova et al., 1994; Ayaz et al., 2005]. Briefly, natural Caucasian blueberry and bilberry fruits were lyophilized, homogenized in liquid $\mathrm{N}_{2}$ and ground in $80 \%$ $\mathrm{MeOH}(\mathrm{v} / \mathrm{v}, 20 \mathrm{~mL})$ containing 2,6-di-tert-butyl- $\beta$-cresol with an electrical high-speed blender. The filtrate was evaporated and re-dissolved in water acidified to $\mathrm{pH} 2$ with $\mathrm{HCl}$. Free phenolic acids were extracted into diethylether. The remaining aqueous phase was split into two parts, hydrolyzed by either $2 \mathrm{~mol} / \mathrm{L} \mathrm{NaOH}$ or $6 \mathrm{~mol} / \mathrm{L} \mathrm{HCl}$, and extracted with diethylether after adjustment to $\mathrm{pH} 2$.

\section{Determination of phenolic acids by UPLC-MS/MS}

Phenolic acids were analyzed using the ACQUITY U1tra Performance LC $^{\text {тм}}$ system (Waters, Milford, MA, USA) linked to a Micromass Quattro micro ${ }^{\mathrm{TM}}$ API bench top triple quadrupole mass spectrometer (Waters MS Technologies, Manchester, UK). Sample solutions were injected into a reversed phase column $(\mathrm{BEH} \mathrm{C} 8,1.7 \mu \mathrm{m}, 2.1 \times 150 \mathrm{~mm}$, Waters, Milford, MA) maintained at $30^{\circ} \mathrm{C}$. The mobile phase consisted of the following 9.5-min sequence of linear gradients and isocratic flows of solvent B (acetonitrile) balanced with aqueous $7.5 \mathrm{mmol} / \mathrm{L} \mathrm{HCOOH}$ (solvent A) at a flow rate of $250 \mu \mathrm{L} / \mathrm{min}$ : $5 \% \mathrm{~B}$ for $0.8 \mathrm{~min}, 5-10 \% \mathrm{~B}$ over $0.4 \mathrm{~min}$, isocratic $10 \%$ B for $0.7 \mathrm{~min}, 10-15 \% \mathrm{~B}$ over $0.5 \mathrm{~min}$, isocratic $15 \% \mathrm{~B}$ for $1.3 \mathrm{~min}, 15-21 \%$ over $0.3 \mathrm{~min}$, isocratic $21 \% \mathrm{~B}$ for $1.2 \mathrm{~min}, 21-27 \% \mathrm{~B}$ over $0.5 \mathrm{~min}, 27-50 \%$ B over $2.3 \mathrm{~min}$, $50-100 \%$ B over $1 \mathrm{~min}$, and finally $100-5 \%$ B over $0.5 \mathrm{~min}$. At the end of this sequence, the column was equilibrated in initial conditions for $2.5 \mathrm{~min}$. The effluent was introduced into an electrospray source operating in negative ion mode (source block temperature $100^{\circ} \mathrm{C}$, desolvation temperature $350^{\circ} \mathrm{C}$, capillary voltage $2.5 \mathrm{kV}$ and cone voltage $25 \mathrm{~V}$ ). Argon was used as collision gas (collision energy $16 \mathrm{eV}$ ) and nitrogen as desolvation gas (500 L h-1). Analytes were quantified using deuterium-labeled internal standards of 4-hydroxybenzoic $(2,3,5,6-\mathrm{D} 4)$ and salicylic $(3,4,5,6-\mathrm{D} 4)$ acids as described elsewhere [Gruz et al., 2008].

\section{Oxygen Radical Absorbance Capacity (ORAC) assay}

Oxygen radical absorbance capacity (ORAC) was determined as described elsewhere [Ou et al., 2001]. Briefly, $100 \mu \mathrm{L}$ of $500 \mathrm{nmol} / \mathrm{L}$ fluorescein and $25 \mu \mathrm{L}$ of diluted extracts were pipetted into each working well of the microplate. Next, $25 \mu \mathrm{L}$ of $250 \mathrm{mmol} / \mathrm{L} \mathrm{AAPH}$ was added, the microplate was shaken for $5 \mathrm{~s}$, and the fluorescence (excitation and emission wavelengths $485 \mathrm{~nm} 510 \mathrm{~nm}$, respectively) was read every 3 min for 90 min using Multiskan Ascent (Labsystems, Helsinki, Finland). Net area under the curve was used to calculate antioxidant capacity expressed as Trolox equivalents (TE).

\section{Statistical analysis}

Statistical analysis was performed using Statistica version 7.0 (StatSoft 2000) in order to determine $p$ values. All data were expressed as mean \pm standard error mean (SEM) from three independent samples in triplicate.

\section{RESULTS AND DISCUSSION}

\section{pH and titratable acidity (pH, TA)}

The $\mathrm{pH}$ and TA differed significantly $(\mathrm{P}<0.05$, Table 1$)$ between the two wild berries. Bilberry ( $V$. myrtillus) fruit had higher $\mathrm{pH}$ (2.71) and lower TA (1.58 g CAE/100 g FW) values compared to Caucasian blueberry $(\mathrm{pH}=2.48$ and $\mathrm{TA}=1.67 \mathrm{~g}$ $\mathrm{CAE} / 100 \mathrm{~g} \mathrm{FW}$ ). Our values for the $\mathrm{pH}$ and TA obtained from the berries used are in good agreement with, and within the ranges of, those reported in previous studies [Kalt \& McDonald, 1996; Lee et al., 2004b; Giovanelli \& Buratti, 2009; Nestby et al., 2011].

\section{Total phenolic (TP) content}

The variations in TP content between the two species of berry are presented in Table 1 . The contents varied significantly $(\mathrm{P}<0.05$, Table 1$)$, with a $10 \%$ higher TP content in bilberry fruit compared to Caucasian blueberry. Reported data (fresh weight, FW) for TP content in wild, cultivated blueberries and bilberries exhibit a wide range, from 81 to 3820 mg GAE/100 g FW [Moyer et al., 2002; Sellappan et al., 2002; Zheng \& Wang, 2003; Lee et al., 2004a, b; Ta- 
TABLE 1. Antioxidant capacity (ORAC), titratable acidity (TA), total phenolics (TP) and total anthocyanin (TAC) contents of berries of Caucasian blueberry (V. arctostaphylos) and bilberry $(V \text {. myrtillus })^{\mathrm{a}}$.

\begin{tabular}{lcccc}
\hline & $\begin{array}{c}\text { Caucasian blueberry } \\
\text { (V. arctostaphylos) }\end{array}$ & $\begin{array}{c}\text { Bilberry } \\
(\text { V. myrtillus })\end{array}$ & P-value \\
\hline $\mathrm{pH}$ & $2.48 \pm 0.01$ & $2.71 \pm 0.02$ & $<0.05$ \\
$\mathrm{TA}^{\mathrm{b}}$ & $1.67 \pm 0.02$ & $1.58 \pm 0.01$ & $<0.05$ \\
$\mathrm{TP}^{\mathrm{c}}$ & $2494.26 \pm 5.42$ & $2686.24 \pm 6.91$ & $<0.05$ \\
$\mathrm{TAC}^{\mathrm{d}}$ & $361.9 \pm 1.6$ & $756.3 \pm 5.7$ & $<0.05$ \\
ORAC $^{\mathrm{e}}$ & $274.6 \pm 8.64$ & $251.6 \pm 9.99$ & $<0.05$ \\
$\mathrm{TAC} / \mathrm{TP}$ & 0.15 & 0.28 & $\mathrm{NE}^{*}$ \\
\hline
\end{tabular}

aValues represent the mean of three separate extractions and determinations; *NE (no evaluated); ${ }^{\mathrm{b}}$ Titratable acidity (TA) expressed as g of citric acid equivalents (CAE) / $100 \mathrm{~g}$ of FW. ${ }^{c}$ Total phenolics (TP) expressed as $\mathrm{mg}$ of gallic acid equivalents (GAE) /100 $\mathrm{g}$ of FW. ${ }^{\mathrm{d} T o t a l}$ anthocyanin (TAC) content expressed as $\mathrm{mg}$ of cyanidin 3-glucoside equivalents (C3G)/100 g of FW. ${ }^{e} \mathrm{ORAC}$ expressed as $\mu$ mol Trolox equivalents (TE) / g of FW.

ruscio et al., 2004; Rodrigues et al., 2011; Jovančević et al., 2011]. For berries of Caucasian blueberry, Koca \& Karadeniz [2009] reported TP contents between 308 and $542 \mathrm{mg}$ $\mathrm{GAE} / 100 \mathrm{~g}$ FW. Their findings were restricted to one location and were much lower than our findings for Caucasian blueberry. The present study reports a high TP content for berries collected from a wide range of populations (Figure 1). Our values concur with some previous studies reporting high TP contents; for instance, Zheng \& Wang [2003] reported a high content TP (2556 mg GAE/100 g FW) in wild chokeberries. Lee et al. [2004b] compared TP contents in two Vaccinium species and reported markedly high TP content for evergreen huckleberry ( $V$. ovatum Pursh) (1169 mg GAE/100 g FW), while black-leaf huckleberry ( $V$. membranaceum Douglas ex Hooker) contained 617 mg GAE/100 g FW. Relatively low TP content (577 and $614 \mathrm{mg}$ GAE/100 g FW) for two bilberry [Giovanelli \& Buratti, 2009] and one blueberry, cranberry and lingonberry (315-652 GAE/100 g FW) cultivars [Zheng \& Wang, 2003] have also been reported.

The corresponding TP content values differed significantly ( $\mathrm{P}<0.05$, Table 2$)$ among sugar/acid fraction, polyphenolic fraction and anthocyanin fraction; being low in the sugar/acid and polyphenolic fractions and high in anthocyanin fractions. Our findings are in general agreement with the work of Lee et al. [2004a]. They also further fractionated the berry extracts of the above two huckleberries (black-leaf and evergreen huckleberries) and reported lower TP content from the anthocyanin fraction (241 and $625 \mathrm{mg} \mathrm{GAE} / 100 \mathrm{~g} \mathrm{FW}$ ) compared to polyphenolic fraction (153 and $354 \mathrm{mg}$ GAE/100 g FW) and sugar/acid fraction ( 8 and $41 \mathrm{mg}$ GAE/100 g FW).

\section{Total anthocyanins (TAC)}

The total anthocyanin contents in the two Turkish blueberries varied significantly $(\mathrm{P}<0.05$, Table 1$)$. The higher (approximately 2.1-fold) TAC content was obtained from bilberry. TAC content values for a wide range of wild and cultivated blueberries have been reported between 11 and $563 \mathrm{mg}$ C3G/100 g FW [Rodrigues et al., 2011; Moyer et al., 2002;
TABLE 2. Antioxidant capacity (ORAC), total phenolics (TP) and total anthocyanin (TAC) contents in fractions obtained from extracts of Caucasian blueberry (V. arctostaphylos) and bilberry (V. myrtillus) by solidphase extraction (SPE).

\begin{tabular}{|c|c|c|c|}
\hline & $\begin{array}{c}\text { Caucasian blueberry } \\
\text { (V. arctostaphylos) }\end{array}$ & $\begin{array}{c}\text { Bilberry } \\
(V . \text { myrtillus })\end{array}$ & $P$-value \\
\hline \multicolumn{4}{|c|}{ Sugar/acid fraction } \\
\hline $\mathrm{TP}^{\mathrm{a}}$ & $19.47 \pm 0.98$ & $14.05 \pm 0.72$ & $<0.05$ \\
\hline $\mathrm{TAC}^{\mathrm{b}}$ & n.d. & n.d. & $\mathrm{NE}^{*}$ \\
\hline $\mathrm{ORAC}^{\mathrm{c}}$ & $30.0 \pm 2.64$ & $29.7 \pm 0.63$ & $\mathrm{NS}^{* *}$ \\
\hline \multicolumn{4}{|c|}{ Polyphenolic fraction } \\
\hline $\mathrm{TP}^{\mathrm{a}}$ & $83.15 \pm 2.36$ & $36.9 \pm 1.55$ & $<0.05$ \\
\hline $\mathrm{TAC}^{\mathrm{b}}$ & $0.57 \pm 0.04$ & $0.60 \pm 0.10$ & NS** \\
\hline $\mathrm{ORAC}^{\mathrm{c}}$ & $57.0 \pm 0.27$ & $47.8 \pm 1.48$ & $<0.05$ \\
\hline \multicolumn{4}{|c|}{ Anthocyanin fraction } \\
\hline $\mathrm{TP}^{\mathrm{a}}$ & $340.92 \pm 3.18$ & $362.70 \pm 3.70$ & $<0.05$ \\
\hline $\mathrm{TAC}^{\mathrm{b}}$ & $170.62 \pm 3.3$ & $280.98 \pm 2.22$ & $<0.05$ \\
\hline $\mathrm{ORAC}^{\mathrm{c}}$ & $80.9 \pm 4.78$ & $142.0 \pm 12$ & $<0.05$ \\
\hline
\end{tabular}

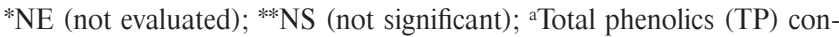
tent expressed as mg of gallic acid equivalents (GAE) /100 g of FW. ${ }^{\mathrm{b}} \mathrm{To}-$ tal anthocyanin (TAC) content expressed as mg of cyanidin 3-glucoside equivalents $(\mathrm{C} 3 \mathrm{G}) / 100 \mathrm{~g}$ of $\mathrm{FW}$. ' $\mathrm{ORAC}$ expressed as $\mu \mathrm{mol}$ Trolox equivalents (TE) / g of FW.

Sellappan et al., 2002; Zheng \& Wang, 2003; Lee et al., 2004b; Taruscio et al., 2004]. However, Koca \& Karadeniz [2009] reported a TAC content of 59-294 mg C3G/100 g FW. Those authors sampled fruit from one location in the Black Sea region (Güneysu, Rize). For bilberries, reported values of TAC in the literature range from 270 to $460 \mathrm{mg} \mathrm{C} 3 \mathrm{G} / 100 \mathrm{~g} \mathrm{FW}$ [Jovančević et al., 2011]. Generally, bilberries have been reported to have the highest anthocyanin contents among $\mathrm{Vac}$ cinium species [Primetta et al., 2013].

Corresponding TAC content values were obtained from further fractionated berry extracts using SPE. These provided sugar/acid, polyphenolic and anthocyanin fractions. Neither Caucasian blueberry nor blueberry had any measurable TAC content in the sugar/acid fraction, whereas the polyphenolic fractions of the same berries had very low TAC content, but were not significantly different. However, the anthocyanin fraction of both berries had considerable TAC content $(\mathrm{P}<0.05$, Table 2). An interspecies difference in TAC content in the sugar/acid fraction, polyphenolic fraction and anthocyanin fraction in berries of two huckleberries berries, $V$. membranaceum and V. ovatum, was reported by Lee et al. [2004b].

The major anthocyanin of Caucasian blueberry and bilberry is delphinidin (583.6 and $972 \mathrm{mg} / 100 \mathrm{~g} \mathrm{DW}$ ) [Lätti et al., 2009; Primetta et al., 2013]. The anthocyanin profiles of the two species have also been reported to exhibit no latitudinal, longitudinal or altitudinal effects, either in contents or in the proportions of aglycones and total anthocyanins [Lätti et al., 2008, Primetta et al., 2013]. The only significant differences reported were in the aglycone-sugars (e.g., galactosides and arabinosides) and the proportions of delphini- 
TABLE 3. Content of phenolic acid ( $\mu \mathrm{g} / \mathrm{g}$ fresh weight) in Caucasian blueberry (V.arctostaphylos) and bilberry (V.myrtillus) ${ }^{\mathrm{a}}$.

\begin{tabular}{|c|c|c|c|c|c|c|c|c|}
\hline \multirow{2}{*}{ Phenolic acid } & \multicolumn{4}{|c|}{ Caucasian blueberry V. arctostaphylos } & \multicolumn{4}{|c|}{ Bilberry V. myrtillus } \\
\hline & Free & Ester & Glycosides & $\mathrm{S}^{\mathrm{b}}$ & Free & Ester & Glycoside & $\mathrm{S}^{\mathrm{b}}$ \\
\hline \multicolumn{9}{|c|}{ Hyroxybenzoic acid derivatives (HBAs) } \\
\hline Gallic acid & nd & $16.80 \pm 0.84$ & $0.82 \pm 0.07$ & 17.62 & nd & $13.95 \pm 1.54$ & $1.39 \pm 0.01$ & 15.3 \\
\hline Protocatechuic acid & $0.05 \pm 0.00$ & $8.60 \pm 0.36$ & $0.63 \pm 0.12$ & 9.28 & $0.81 \pm 0.04$ & $19.68 \pm 2.42$ & $2.83 \pm 0.02$ & 22.51 \\
\hline p-Hydroxybenzoic acid & nd & $0.09 \pm 0.00$ & $0.1 \pm 0.02$ & 0.19 & nd & $0.16 \pm 0.06$ & $0.23 \pm 0.03$ & 0.39 \\
\hline Salicylic acid & nd & nd & $0.66 \pm 0.11$ & 0.66 & nd & nd & $0.52 \pm 0.01$ & 0.52 \\
\hline Vanillic acid & nd & $1.59 \pm 0.07$ & nd & 1.59 & nd & $2.64 \pm 0.36$ & $0.79 \pm 0.00$ & 3.43 \\
\hline Syringic acid & nd & $45.53 \pm 3.28$ & nd & 45.53 & nd & $27.04 \pm 5.98$ & nd & 27.04 \\
\hline \multicolumn{9}{|c|}{ Hyroxycinnamic acid derivatives (HCAs) } \\
\hline Caffeic acid & $0.34 \pm 0.01$ & $968.05 \pm 27$ & $25.20 \pm 7.20$ & 993.59 & $0.38 \pm 0.00$ & $128.99 \pm 15.56$ & $14.24 \pm 1.16$ & 143.61 \\
\hline$p$-Coumaric acid & $0.29 \pm 0.00$ & $129.39 \pm 1.82$ & $13.16 \pm 3.42$ & 142.84 & $0.32 \pm 0.00$ & $119.24 \pm 12.30$ & $36.58 \pm 2.89$ & 156.14 \\
\hline Ferulic acid & nd & $3.21 \pm 0.31$ & $0.59 \pm 0.05$ & 3.8 & nd & $3.54 \pm 1.073$ & $3.30 \pm 0.13$ & 6.84 \\
\hline Chlorogenic acid ${ }^{c}$ & $0.19 \pm 0.04$ & nd & $36.82 \pm 7.47$ & 37.01 & nd & nd & $8.94 \pm 0.47$ & 8.94 \\
\hline$\Sigma$ HBAs & 0.05 & 72.61 & 2.21 & 74.87 & 0.81 & 63.47 & 5.76 & 69.19 \\
\hline$\Sigma$ HCAs & 0.82 & 1100.65 & 75.77 & 1177.24 & 0.7 & 251.77 & 63.06 & 315.53 \\
\hline $\begin{array}{l}\Sigma \text { PHAs } \\
(\text { HBAs }+ \text { HCAs })\end{array}$ & 0.87 & 1173.26 & 77.98 & 1252.11 & 1.51 & 315.24 & 68.82 & 384.72 \\
\hline
\end{tabular}

${ }^{a}$ Each value represents the average from duplicate extraction and determination. Values expressed are means \pm SD. S ${ }^{\mathrm{b}}$ Total refers to the sum of individual phenolic acids. ${ }^{c}$ Ester of caffeic acid + quinic acid.

din values. Average content of delphinidin was calculated as $35 \mathrm{mg} \mathrm{C} 3 \mathrm{G} / 100 \mathrm{~g}$ FW in the dark blue-purple berries in some Vaccinium species; half-highbush blueberry ( $V$. angustifolium Aiton x corymbosum L.), highbush blueberry (V. corymbosum L.), oval-leaf blueberry (V. ovalifolium Smith), cascade huckleberry ( $V$. deliciosum Piper), black-leaf huckleberry, evergreen huckleberry, wild cranberry (V. oxycoccus L.) and bog/alpine bilberry (V. uliginosum L.) [Taruscio et al., 2004]. This is lower than the respective content of bilberries [Primetta et al., 2013].

In the present study, an interspecies difference in the TAC/ $\mathrm{TP}$ ratio was determined in berries for both the Caucasian blueberry and bilberry (Table 1 ). A wide range of TAC/TP ratios has been reported in the literature for different Vaccinium berries, ranging from 0.14 to 0.28 [Sellappan et al., 2002; Moyer et al., 2002; Zheng \& Wang, 2003; Lee et al., 2004a,b; Taruscio et al., 2004]. Our values for the TAC/TP ratios for the Caucasian blueberry and bilberry were within the ranges previously reported in the literature. However, remarkably high TAC/TP ratios have also been reported for two bilberry and four highbush blueberry cultivars from Italy [Giovanelli \& Buratti, 2009]. These studies confirmed cultivar or genotype variety, soil, maturity season and geographical region as affecting the TAC/TP ratio in Vaccinium berries.

\section{Phenolic acids (PHAs)}

Phenolic acids present in berries were analyzed using UPLC-MS/MS (Table 3). Of the 10 compounds identified, nine were simple phenolic acids and the other was chlorogenic acid (ChA), an ester of quinic acid and caffeic acid.
Fruits of both species were characterized by different quantities of individual free phenolic acids and liberated from ester and glycosidic bonds. Six hydroxybenzoic acids (HBAs), including gallic acid (GaA), protocatechuic acid (PA), p-hydroxybenzoic acid ( $p \mathrm{HBA})$, salicylic acid (SA), vanillic acid (VA) and syringic acid (SyA), as well as four hydroxycinnamic acids (HCAs), including caffeic acid (CaA), p-coumaric acid $(p \mathrm{CoA})$, ferulic acid (FA) and chlorogenic acid (ChA), were identified and quantified (Table 3 ). The most significant finding with respect to the phenolic acid content of the two wild Vaccinium species from the northern and western regions of Turkey (Figure 1) was the quantity of $\mathrm{CaA}$ and $p \mathrm{CoA}$ in the ester and glycoside forms. SyA was present in berries only in the ester form. Among HBA derivatives, GaA was the second most abundant phenolic acid present in the ester form. Caucasian blueberry had higher total HBAs and HCAs contents in the ester form than the bilberry (Table 3 ).

The presence of gallic, protocatechuic, $p$ - and $m$-hydroxybenzoic, gentisic, syringic, salicyclic, $p$-, $m$ - and $o$-coumaric, caffeic, ferulic, and sinapic acids in Vaccinium berries in varying quantities has been reported in several studies [as reviwed by Ayaz et al., 2005; Lätti et al., 2011; Ieri et al., 2013, respectively]. Among these phenolic acids, in general, caffeic acid, ferulic acid, $p$-coumaric acid and gallic acid have been identified as the major common phenolic acids in a wide range of Vaccinium berries, also in the form of free, ester and glycoside forms [as reviwed by Ayaz et al., 2005; Zadernowski et al., 2005, respectively]. Our findings concur with the above studies in that the two berries investigated contain $p$-coumaric 
TABLE 4. Antioxidant activity (ORAC) of phenolic acid fractions obtained from extracts of Caucasian blueberry ( $V$. arctostaphylos) and bilberry $(\text { V. myrtillus })^{\mathrm{a}}$.

\begin{tabular}{lcccc}
\hline $\begin{array}{l}\text { Phenolic } \\
\text { acid form }\end{array}$ & $\begin{array}{c}\text { Caucasian blueberry } \\
\text { V.arctostaphylos }\end{array}$ & $\begin{array}{c}\text { Bilberry } \\
\text { V. myrtillus }\end{array}$ & $P$-value \\
\hline Free & 16.24 & 6.21 & $<0.05$ \\
Ester & 54.78 & 135.32 & $<0.05$ \\
Glycoside & 23.82 & 34.58 & $<0.05$ \\
\hline
\end{tabular}

aexpressed as $\mu \mathrm{mol}$ Trolox equivalents (TE) / g of FW.

acid and caffeic acid as the major phenolic acids in the free, ester and glycoside forms and exhibited intra- and interspecies difference.

A significant amount of chlorogenic acid (ChA) was determined in the glycoside fraction extract of berries of the Caucasian blueberry (Table 3). The same acid was also found in bilberry berries, but in quite low amounts. Marked interand intraspecies differences have been reported in the content of ChA among 9 Vaccinium species $(50.9-1414 \mathrm{mg} / \mathrm{g}$ FW) [Taruscio et al., 2004]. Those authors did not report any detectable levels of the acid in berries of alpine bilberry (V. uliginosum L.). Compared to berries of cranberry (V. macrocarpon Ait cv. 'Ben Lear') and lingonberry (V. vitis-idea L. cv. 'Amberland'), Zheng \& Wang [2003] noted a high content of ChA in berries of blueberry ( $V$. corymbosum L. cv. 'Sierra') at $645.9 \mathrm{mg} / \mathrm{g} \mathrm{FW}$.

\section{Antioxidant capacity}

Total antioxidant capacity was measured using ORAC. The values differed significantly $(\mathrm{P}<0.05)$ between Caucasian blueberry and bilberry (Table 1-4). A 10\% higher ORAC value was determined for Caucasian blueberry (274.6 $\mu \mathrm{mol} \mathrm{TE} / \mathrm{g} \mathrm{FW}$ ), whereas the ORAC value for the bilberry was $251.4 \mu \mathrm{mol} \mathrm{TE} / \mathrm{g}$ FW. Our results seem rather high, with a $\sim 2$-fold higher ORAC value for berry species, compared to lowbush blueberry (V. angustifolium Aiton) [Moyer et al., 2002]. Intra- and interspecies differences have been reported in ORAC values between different blueberry phenolic extracts. For instance, the ORAC values reported by Lee et al. [2004a], Taruscio et al. [2004] and Moyer et al. [2002] were 26.2, 21.0 and $38.7 \mu \mathrm{mol} \mathrm{TE} / \mathrm{g} \mathrm{FW}$ for black-leaf huckleberry, and 103.4, 41.1 and $69.8 \mu \mathrm{mol} \mathrm{TE} / \mathrm{g} \mathrm{FW}$ for evergreen huckleberry, respectively. For the fruits of red huckleberry these were 78.0 and $7.3 \mu \mathrm{mol} \mathrm{TE} / \mathrm{g} \mathrm{FW}, 87.8$ and $30.5 \mu \mathrm{mol} \mathrm{TE} / \mathrm{g}$ FW for lowbush blueberry, 52.3 and $21.4 \mu \mathrm{mol} \mathrm{TE} / \mathrm{g}$ FW for highbush blueberry and 48.0 and $37.8 \mu \mathrm{mol}$ TE/g FW for oval-leaf blueberry [Moyer et al., 2002; Taruscio et al., 2004].

The results of the antioxidant activity assays of the fractions obtained after separation of extracts of phenolic compounds from berries on the $\mathrm{C} 18$ column are presented in Table 2. The ORAC values for the sugar/acid fractions of the two berries were not significantly different $(\mathrm{P}<0.05)$ (Table 2$)$, whereas the ORAC values for polyphenolic and anthocyanin fractions varied significantly $(\mathrm{P}<0.05)$ (Table 2). Similarly, Lee et al. [2004b] observed an increasing trend in ORAC values for the two huckleberries (black-leaf and evergreen), measured at 3.1 and 6.3 for sugar/acid fraction, 9.9 and 24.8 for polyphenolic fraction and 15.7 and $44.9 \mu \mathrm{mol} \mathrm{TE} / \mathrm{g} \mathrm{FW}$ for the anthocyanin fraction, respectively.

Table 4 shows that the ORAC values for the fractions of free phenolic acid and phenolic acids liberated from ester and glycoside forms differed significantly $(\mathrm{P}<0.05)$ among the Caucasian blueberry and wild bilberry fruits. Except for the free form, the bilberry extract exhibited higher ORAC values both in ester and glycoside fractions of phenolic acids than those of Caucasian bilberry in the same form. No comparable data exist for further discussion between ORAC capacity and phenolic acids investigated in Vaccinium berries/fruits.

Overall, our findings are in general agreement with previous studies in terms of TP, TAC and ORAC values and phenolic acids in Vaccinium species. However, there were also some considerable differences between our findings and previously reported data. A large body of literature now clearly shows that profiles of phenolics are influenced by various abiotic and biotic factors (temperature, irradiation, herbivory, pathogenic infection, etc.). In addition, numerous research groups have reported that differences in anthocyanin and phenolic contents in parallel with antioxidant capacities in berries of Vaccinium (cultivar, genotype, soil, clones, etc.) are due to growing season and environmental factors [Selappan et al., 2002; Lee et al., 2004b]. Variations between our results and reported data concerning berry phenolics can therefore be largely explained in terms of maturity, soil type and geography etc., as reported by Prior et al. [1998].

\section{CONCLUSION}

Considerable variation in antioxidant activity (ORAC) was determined in phenolics, further fractioned phenolic fractions and phenolic acid forms (free, ester and glycoside) in this study. The berries of bilberry had higher TAC and TP contents and $\mathrm{pH}$ values than the Caucasian blueberry. The three different phenolic fractions (further fractioned phenolics) obtained by SPE differed significantly, except for the sugar/acid fraction. The phenolic acid profiles of each native berries were distinctive in the free, ester and glycoside fractions, especially caffeic acid, being the major phenolic acid in ester form in both Caucasian blueberry and bilberry, followed by $p$-coumaric acid. An increasing trend in TP and TAC contents results in an increased antioxidant capacity (ORAC) in each berry extract, being highest in the polyphenolic fraction in the berries of Caucasian blueberry and in the anthocyanin fraction in berries of bilberry. Due to their TP and TAC contents, both Caucasian blueberry and bilberry may represent an additional source of antioxidants for the fresh market and commercial processing. Our findings also confirm that $V$. myrtillus (bilberry) has one of the highest anthocyanin levels of berries examined to date. Moreover, the present findings can be evaluated in breeding programs in order to obtain Vaccinium cultivars with high phenolic and antioxidant capacities.

\section{ACKNOWLEDGEMENTS}

Financial support for this study was provided by the Research Fund of Karadeniz Technical University (Project No: 2005.111.004.02). The authors Faik Ahmet Ayaz and Huseyin 
Inceer also greatly appreciate the support from the Council of Higher Education of Turkey (CoHE). This work was also financially supported by the Ministry of Education, Youth and Sports of the Czech Republic through the National Program of Sustainability (grant no. LO1204).

\section{REFERENCES}

1. AOAC INTERNATIONAL, 2003. AOAC Official Methods Program Manual, [www.aoac.org/vmeth/omamanual/omamanual.htm].

2. Ayaz F.A., Hayirlioglu-Ayaz S., Gruz J., Novak O., Strnad M., Separation, characterization, and quantitation of phenolic acids in a little-known blueberry (Vaccinium arctostaphylos L.) fruit by HPLC-MS. J. Agr. Food Chem., 2005, 53, 8116-8122.

3. Cvikrová M., Hrubcová M., Vágner M., Machácková I., Eder J., Phenolic acids and peroxidase activity in alfalfa (Medicago sativa) embryonic cultures after ethephon treatment. Physiol. Plantarum, 1994, 91, 226-233.

4. Giovanelli G., Buratti S., Comparison of polyphenolic composition and antioxidant activity of wild Italian blueberries and some cultivated varieties. Food Chem., 2009, 112, 903-908.

5. Giusti M.M., Wrolstad R.E., Unit F1.2: Anthocyanins, characterization and measurement with UV-visible spectroscopy. 2001, in: Current Protocols in Food Analytical Chemistry (ed. R.E. Wrolstad). John Wiley \& Sons: New York, pp. 1-13.

6. Gruz J., Novák O., Strnad M., Rapid analysis of phenolic acids in beverages by UPLC-MS/MS. Food Chem., 2008, 111, 789-794.

7. Ieri F., Martini S, Innocenti M., Mulinacci N., Phenolic distribution in liquid preparations of Vaccinium myrtillus L. and Vaccinium vitis-idaea L. Phytochem. Anal., 2013, 24, 467-475.

8. Jovančević M., Balijagić J., Menković N., Šavikin K., Zdunić G., Janković T., Dekić-Ivanković M., Analysis of phenolic compounds in wild population of bilberry (Vaccinium myrtillus L.) from Montenegro. J. Med. Plants Res., 2011, 5, 910-914.

9. Kalt W., McDonald J.E., Chemical composition of lowbush blueberry cultivars. J. Am. Soc. Hortic. Sci., 1996, 121, 142-146.

10. Koca I., Karadeniz B., Antioxidant properties of blackberry and blueberry fruits grown in the Black Sea Region of Turkey. Sci. Hortic., 2009, 121, 447-50.

11. Lätti A.K., Kainulainen P.S., Hayirlioglu-Ayaz S., Ayaz F.A., Riihinen K.R., Characterization of anthocyanins in Caucasian blueberries (Vaccinium arctostaphylos L.) native to Turkey. J. Agric. Food Chem., 2009, 57, 5244-5249.

12. Lätti A.K., Riihinen K.R., Jaakola L., Phenolic compounds in berries and flowers of a natural hybrid between bilberry and lingonberry (Vaccinium $\times$ intermedium Ruthe). Phytochemistry, 2011, 72, 810-815.

13. Lätti A.K., Riihinen K.R., Kainulainen P.S., Analysis of anthocyanin variation in wild populations of bilberry (Vaccinium myrtillus L.) in Finland. J. Agric. Food Chem., 2008, 56, 190-196.

14. Lee J., Finn C.E., Wrolstad R.E., Comparison of anthocyanin pigment and other phenolic compounds of Vaccinium membranaceum and Vaccinium ovatum native to the Pacific Northwest of North America. J. Agric. Food Chem., 2004a, 52, 7039-7044.

15. Lee J., Finn C.E., Wrolstad R.E., Anthocyanin pigment and total phenolic content of three Vaccinium species native to the Pacific Northwest of North America. HortScience, 2004b, 39, 959-964.

16. Li R., Wang P., Guo Q.Q., Wang Z.Y., Anthocyanin composition and content of the Vaccinium uliginosum berry. Food Chem., 2011, 125, 116-120.

17. Moyer R.A., Hummer K.E., Finn C.E., Frei B., Wrolstad R.E., Anthocyanins, phenolics, and antioxidant capacity in diverse small fruits: Vaccinium, Rubus, and Ribes. J. Agric. Food Chem., 2002, 50, 519-525.

18. Nestby R., Percival D., Martinussen I., Opstad N., Rohloff J., The European blueberry (Vaccinium myrtillus L.) and the potential for cultivation. A review. Eur. J. Plant Sci. Biotechnol., 2011, 5, 5-16.

19. Ou B., Hampsch-Woodill M., Prior R.L., Development and validation of an improved oxygen radical absorbance capacity assay using fluorescein as the fluorescent probe. J. Agric. Food Chem., 2001, 49, 4619-4626.

20. Primetta A.K., Jaakola L., Ayaz F.A., Inceer H., Riihinen K.R., Anthocyanin fingerprinting for authenticity studies of bilberry (Vaccinium myrtillus L.). Food Control, 2013, 30, 662-667.

21. Prior R.L., Cao G., Martin A., Sofic E., McEwen J., O'Brien C., Lischner N., Ehlenfeldt M., Kalt W., Krewer G., Mainland C.M., Antioxidant capacity as influenced by total phenolics and anthocyanin content, maturity, and variety of Vaccinium species. J. Agric. Food Chem., 1998, 46, 2686-2693.

22. Rodrigues E., Poerner N., Rockenbach I.I., Phenolic compound and antioxidant activity of blueberry cultivars grown in Brazil. Cienc. Technol. Aliment., 2011, 31, 911-917.

23. Rodriguez-Saona L.E., Wrolstad R.E., Unit F1.1. Extraction, isolation, and purification of anthocyanins, 2001, in: Current Protocols in Food Analytical Chemistry (ed. R.E Wrolstad). John Wiley \& Sons: New York, pp. 1-11.

24. Sellappan S., Akoh C.C., Krewer G., Phenolic compounds and antioxidant capacity of Georgia-Grown blueberries and blackberries. J. Agric. Food Chem., 2002, 50, 2432-2438.

25. Slinkard K., Singleton V.L., Total phenol analysis: automation and comparison with manual methods. Am. J. Enol. Viticult, 1977, 28, 49-55.

26. Su Z., Anthocyanins and flavonoids of Vaccinium L. Pharmaceut. Crops, 2012, 3, 7-37.

27. Taruscio T.G., Barney D.L., Exon J., Content and profile of flavanoid and phenolic acid compounds in conjunction with the antioxidant capacity for a variety of Northwest Vaccinium berries. J. Agric. Food Chem., 2004, 52, 3169-3176.

28. Yuan W., Zhou L., Deng G., Wang P., Creech D., Li S., Anthocyanins, phenolics and antioxidant capacity of Vaccinium L. in Texas, USA. Pharmaceut. Crops, 2011, 2, 11-23.

29. Zadernowski R., Naczk M., Nesterowicz J., Phenolic acid profiles in some small berries. J. Agric. Food Chem., 2005, 53, 2118-2124.

30. Zheng W., Wang S.Y., Oxygen radical absorbing capacity of phenolic in blueberries, cranberries, chokeberries and lingonberries. J. Agric. Food Chem., 2003, 51, 502-509.

Submitted: 3 July 2014. Revised: 23 October 2014, 9 April 2015, 1 October 2015. Accepted: 2 November 2015. Published on-line: 31 March 2016. 
